\title{
Growth and learning mechanisms in the evolving multilayered and multidimensional view of international entrepreneurship
}

\author{
Hamid Etemad ${ }^{1}$
}

Published online: 27 March 2018

(C) Springer Science+Business Media, LLC, part of Springer Nature 2018

\section{Introduction}

This issue celebrates the conclusion of 15 year of continuous and successful publishing in the Journal of International Entrepreneurship and the beginning of the 16th year with volume 16. As in the past, this volume will explore new topics and meet the challenges of new research frontiers to broaden and deepen the field and this note will not be an exception.

The common theme cutting across the four articles following this article is the general topic of evolutionary paths of entrepreneurial internationalization in terms of gaining incremental experience, acquiring incremental knowledge and learning, among other components and mechanisms that enhance, expand, or hinder the International Entrepreneurship's (IE) evolutionary processes. ${ }^{1}$ As discussed in the previous issues, the environment of entrepreneurial internationalization has not only gradually transformed into a complex multidimensional and multilayered, at the common intersection of which IE agents operate, but is also dynamically evolving rapidly as the expanding World Wide Web (WWW) and the Internet connections are broadening, deepening, and even transforming their inter-connections. Naturally, such evolutionary processes contribute to making the IE's environmental context equally more complex and challenging for all involved.

\footnotetext{
${ }^{1}$ Although international entrepreneurship has traditionally addressed internationalization processes across environments, firms, geographies, operations, processes, and strategies, among others, the journal's increasing emphasis has been on the entrepreneurial nature of the above processes that would entail entrepreneurial, or innovative, approaches to both the entrepreneurs', and firms', aspirations to attain growth through internationalization, which embrace much beyond international market expansions.
}

Hamid Etemad

hamid.etemad@mcgill.ca

$1 \quad$ McGill University, Montreal, Canada 
This article aims to further build on the interactions and inter-relations of IE's emerging environment by revisiting its related article, entitled "The Emergence of On-line Global Market Place and the Multilayered View of International Entrepreneurship" (Etemad 2017a). That article explored the interaction of on-line layers with their corresponding off-line dimensions (and layers) and examined their added richness and complexities in the multidimensional and multilayered environment that is the de-facto context for international entrepreneurship. A schematic highlighting that environment is re-produced in Fig. 1, below. That article was, in turn, based on a previous piece that had explored IE's traditional environmental context prior to advent of the Internet and integration of off-line and on-line activities (Etemad 2017b). It suggested that both the MNEs and internationalizing SMEs (iSMEs) would face an increasingly complex, dynamic, and rapidly evolving environment that would be adapting to the emerging change, regardless of the source (Etemad 2004). MNEs and iSMEs need to formulate new growth strategies not only for the currently prevailing conditions, but also for the evolving one with the capability of accommodating that evolving environment as well. Therefore, the principal question before us is how to accomplish the task? This article will first draw on the traditional IB theory before searching for growth pathways in the next section.

Structurally and following this brief introduction, this article will unfold as follows. In Part II, it will explore theoretical pathways for growth and internationalization of smaller and younger firms. It then proceeds to point out that digital platform operations, such as Air B and B, among many others, have internalized in a semblance of the proposed multidimensional and multilayered framework. Furthermore, it suggests that these firms have identified evolutionary pathways for growth and are internationalizing rapidly and fruitfully. Selective examples of a few components of the deployed strategies, within the customized framework of the firm, are identified and their respective collaborative growth potential is pointed out. With the aim of portraying documented evolutionary paths for successful internationalization, Part III will also

\section{Contextualized Schematic Representation of selected Disciplines Influencing IE}

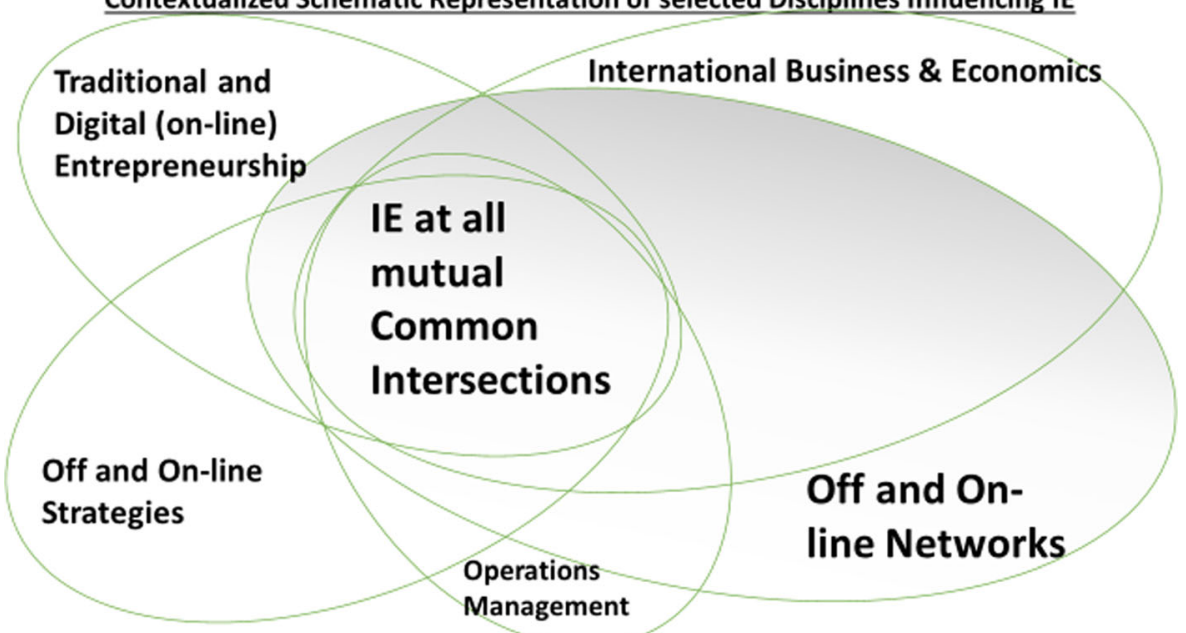

Fig. 1 International entrepreneurship environment at the common intersection of selected influential disciplines contextualized for on- and off-line activities, strategies, and spaces. (Source: Etemad 2017a) 
portray bridging pathways and supporting concepts in the four articles that follow. These portrayals will also point out the barriers that make growth and internationalization challenging. Finally, a brief discussion and conclusion invite scholars to further explore the proposed topics and implied theoretical and scholarly challenges. Public policy implications are suggested at the end.

\section{Theoretical perspectives and the multidimensional and multilayered operational framework}

The process theory perspective Following the urging of many researchers, Johanson and Vahlne (2003) revisited their process theory, also known as the Uppsala, or the Umodel of internationalization (Johanson and Vahlne 1977, 1990). They observed that international competition had intensified and technological developments had accelerated. Due to such environmental changes that are transformable into capabilities, or competitive advantages, new, smaller, and younger firms may have charted-out promising new interstices - i.e., small empty space within, in between, or across the dimensional that would offer promising prospects. Alternatively, firms need to create their own spatial presence and characteristics (e.g., create its own customized on-line presence with distinguishing scope and depth) in relation to other on-line and off-line partners, stake-holders, and their respective activities and devise a trajectory towards the most promising common $\mathrm{g}$ intersections, within which to operate internationally.

Johanson and Vahlne (2003) agreed that "the old models of incremental internationalization are no longer valid" (page 83) and "there is a need for a new model of internationalization" (page 83). The U-model was proposed in 1997 (Johanson and Vahlne 1977) and was based on the interplay of four core concepts and process that governed entry and expansions in the international market, namely, knowledge of market operations, market commitment, commitment decisions, and decisions regarding current activities in a given international (i.e., a local foreign) market. Two complimentary concepts (or constructs) also played moderating and evolutionary roles, i.e., "Psychic Distance" and "Experiential Learning." For example, a low psychic distance (e.g., similar home and host country environments), coupled with high knowledge of the local operations, would facilitate learning about the market and could result in high commitment to the market. Conversely, a combination of high psychic distance and low initial knowledge of the local market would make learning necessary, but more difficult, thus entailing higher perceived risk resulting in a low-risk and low-commitment entry mode, and correspondingly, a low commitment to the market, which could evolve over time. "Experiential learning," could yield incremental acquisition and higher accumulated knowledge of the local operations and justify subsequent higher commitment over time. Such tacit knowledge could only be acquired by establishing a presence in the market and learning by doing in the market through interactions with buyers, suppliers, competitors, and others. Stated differently, the mechanism of learning in general and experiential learning in particular would be critical to evolution and consequent growth in international markets, especially when a firm would be facing increasing complexity and difficulty in the environment.

Similar and parallel research (e.g., Welch and Luostarinen 1988) had distinguished between the general knowledge of internationalization process and, the specific and tacit knowledge of the local market operations, in support of requisite capabilities for 
conducting them internationally and locally, respectively. This stream of early research had pointed to the qualitative differences in the nature of information and capabilities involved. While a firm could build its highly functional capability to conduct, for example, the logistics of international shipping, collection, among others, through collaboration with specialized intermediaries, regardless of the local market characteristics, the specific tacit knowledge of a foreign local market could be acquired collaboratively without a local presence (to enable experiential learning) and operations internalized easily. By implication, therefore, the U-model would not have instructive lessons for smaller and younger firms, facing complex environment and lacking the rich resources and capabilities of their own, for entering those markets for growth and internationalization effectively.

The born globals,' international new ventures,' and rapidly internationalizing enterprises' perspective In contrast to the U-model, the Helsinki Model of internationalization (Welch and Luostarinen 1988) had pointed to firms achieving internationalization by collaborating with specialized external agents, especially when low-risk and low-commitment operations deemed strategically necessary and possibly the most optimal option for smaller and time-compressed firms to internationalize in order to survive, even at home. Indeed, the seminal research in the decade of 1990s (e.g., Rennie 1993, Oviatt and McDougall 1994, McDougall and Oviatt 1994 and 2000, Knight and Cavusgil 2004) identified a family of entrepreneurial SMEs that internationalized rapidly and in early stages of their life cycle by using mostly low market commitment strategies. The research on high growth firms (Etemad 2007; Keen and Etemad 2012; Etemad and Keen 2014; Etemad and Wu 2013) also identified a family of rapidly internationalizing small enterprises (RIEs). These firms internationalized rapidly because of various time pressures arising from rapidly evolving technologies, very high initial fixed costs (Keen and Etemad 2012), and even the top management's shorter and hurried time horizons (Etemad and Wu 2013). Although there is a vast and rich literature on BGs, INVs, and RIEs (e.g., Rialp et al. 2005, Moen and Servais 2002, Zahra 2005, Zahra and George 2002), we abstract from that literature in favor of time and space. Germane to the above discussion, however, is that the internationalizations of most, if not all, firms in this family of enterprises that share the following characteristics, including, but not limited to the following:

i) They recognize attractive opportunities both at home and in international markets, or find it easier to create and exploit opportunities in international markets, but not to the exclusion of home markets

ii) They have a sense of urgency in exploiting that opportunity at home and internationally

iii) They find the environmental and institutional environments challenging

iv) They deploy low-commitment market entry modes, mostly in collaboration with local enterprises, or local agents, which negate the need for high initial capabilities, rich resources, and high perceived risk that young start-up cannot manage

v) Most of their operations require low market knowledge that obviate the need for experiential knowledge in the foreign market place

vi) They mostly seek and learn continuously, rapidly, and vicariously through feedback of others (buyers, suppliers, collaborators, among others) 
vii) They integrate the newly learned knowledge with their previous pool of knowledge to enhance their current capabilities and competitiveness

viii) They use the increasing complexity of the emerging multidimensional and multilayered environment to the their own advantage, by leveraging selective aspects

ix) They increasingly rely on a combination of entrepreneurial capital (Etemad and Keen 2014), high- and disruptive-technologies, and innovative strategies in their internationalization combined with a sense of urgency

Similarly, highly progressively innovative firms are not rare or exceptions as they are created continually and over shadow their predecessors (e.g., BGs and INVs) by capitalizing on the emerging complexities and are exploiting them for their own advantage. ${ }^{2}$ With their increasing access to, and exploitation of, the rapidly expanding Internet-based technologies (IBTs), enhanced by rapidly developing communication and information technologies (CITs), many of such rapidly internationalizing firms (which were smaller start-ups not long time ago) are using the emerging "web-based platform operations" that offer potent innovate and dynamic capabilities, based on the use of machine learning and artificial intelligence, among other advancing technologies. Most of them have not followed traditional growth strategies, and yet, they have become dominant and path-breaking internationalized firms in the past two decades. Other aspiring smaller firms are now emulating their highly competitive and innovative strategies. Such more potent strategies, developed within the past decade, are both disruptive and evolutionary. They include, but are not limited to, families of collaborative co-creations (of designs, production, value, etc.) and active crowd-participations (or crowdsourcing), mainly through the Internet-based technologies and processes (IBTPs), as inputs for strengthening and enriching their digital platform operations, which are capable of continuous learning, leveraging, and integration of the received input in building higher capabilities. Due to their rich diversity, size, lines of activity, and scope of operations, we abstract from discussing them in favor of time and space. However, we portray a hybrid typical profile of such emerging firms, such as Air B and $\mathrm{B}$, or Uber Transport, among many others that have combined crowdsourcing, cocreation, IBTPS, and digital platform operations.

\section{A typical profile of crowd participation in sourcing, co-creation, and tailor-} making Countless, and initially indistinguishable, number of entrepreneurial startups engaged in crowdsourcing as a newly emerging low-cost strategy for achieving higher competitiveness and equally higher value creation in a variety of operations. They utilized crowd participation in varied forms, fully or partially, at their early stages (e.g., starting up funding), intermediate stages (e.g., design, redesign, and tailor-making of products and service), and later stages of their supply chain and value creation (e.g., marketing, promotions, and delivery). In turn, crowds voluntarily engaged, for example, in the following:

\footnotetext{
${ }^{2}$ Before closing and integrating the discussion of this part, we point briefly to the increasing emergence of a new genre of enterprises, such as Air B and B, Uber Transport, Café press, Shopify, among others, who have devised their own multidimensional and multilayered operating environment that are consistent with the above articulation of the emerging environment and are contrasting the lessons of traditional IB theories.
} 
i) Participating in the initial start-up funding and subsequent investments (thus reducing the high entrepreneurial start-up and market entry risks)

ii) Supplying information about the location, size, and density of potential markets at home and abroad (thus forming and increasingly updating the market knowledge and reducing market behavior uncertainties without a presence in foreign local markets)

iii) Providing crowd-based innovative ideas for firms' continuing cutting-edge product and service offerings (thus obviating the need for high R\&D outlays and risks, initially and over time)

iv) Assisting in defining fully tailor-made products and services for the ultimate customer to attain highly desired (maximum) perceived value for their use (thus allowing for mass-customization at mass-production prices)

v) Supplying sufficient information to the web-based digital operating "production platforms" to learn continuously and expand, enrich, and update its pool of market and operational knowledge over time to generate increasingly more values (thus obviating the need for onerous learning processes), and with the recent addition of machine learning and artificial intelligence to such platforms

vi) Digital platform operators are transforming individual tacit knowledge originated in the far corners of the world into well-organized pools of institutional knowledge that can be further exploited fruitfully

vii) Crowds are responding to the digital, mobile, and tailor-made marketing of these platform firms in marketing and distribution of their final goods and services, in which the individual members of the crowd had helped to co-create ${ }^{3}$

The above highlights portray typical, emerging, and competitive operations within the firm's own optimized counter part of the broader multidimensional and multilayered environment. Seemingly, however, these newly emerging, but rapidly evolving, operations neither follow the lessons of the traditional international business theory, nor those of the Born Globals' and International New Ventures'. They do, however, engage crowds in implicit collaborative and possibly synergistic arrangements (Dana et al. 2001, 2008), in selective aspects of their evolutionary operations that give them higher competiveness and consequent internationalization over time.

\section{Highlight of articles}

Theoretically, and as stated earlier, the essential question for BGs, INVs, RIEs (Keen and Etemad 2012), and the young field of IE by a logical extension, is as follows:

\footnotetext{
${ }^{3}$ Although, the millennials are large participants in the above, and thus nearly discounted by scholarly circles, the notable fact is that crowd-based information is reversing the flow of information that initiated or support the various component of supply chain and value net in maximizing the ultimate-customer's perceived value. For example, an individual member of the crowd defines the basis of what constitute value, the conditions under which they would like to receive it, use the product or the service, and thus obviates experiential learning in the market place), which constituted as one the principals of the process theory of internationalization (Johanson and Vahlne 1977; Johanson and Vahlne 2003). However a collaborative and synergistic learning ( Dana et al. 2001, 2008) is replacing it and is shifted learning onto the digital operational platform.
} 
What factors, forces, or processes are (and have been from the beginning) enabling the agents of IE to grow and propelling them into international markets, further internationalize at higher rates, and compete with their larger traditional counter parts locally and globally. The authors of the next article in this issue suggest that "learning" is that empowering force behind such growth strategies.

\section{Part II: Highlight of articles}

The second article in this issue is entitled as the "Learning Advantages of Newness: A Reconceptualization and Contingent Framework" co-authored by Shaker A. Zahra, Congcong Zheng, and Jifeng Yu. As the title suggests, the authors invite readers to think of learning as the principal core concept capable of giving added competitive advantage(s) to the new firms that they did not have before. These are firms that are possibly smaller, younger, and not enamored by their legacy operating systems and that are open to new concepts and ideas in and from international markets. The authors term them as the "advantages of newness". In order to stimulate thinking about the article and its insightful and theoretically supported propositions, we approach it from two opposite vantage points, as follows:

First, the emerging connected world that incorporates and operates through the Web 2.0's interactivity, enhanced by the Internet-based technologies and processes (IBTPs) and the communication and information technologies (CITs), among other advancing technological processes, has extended new firms' reach, and easier access, to the global markets. New firms can both promote their goods and services on-line and simultaneously learn about the various market reactions and consequent behaviors, including those of buyers, suppliers, competitors, and other market influencers (e.g., local regulators) through interactive on-line information facilities and services. These amount to additional potent informational resources that new firms could not attain easily a short time ago. Acquiring and exploring information about untapped opportunities, regardless of their time and geographic locations, can be used in forming potent corresponding capabilities for higher competitive advantages through the readily available innovative, and at time disruptive, technologies (e.g., by deploying the emerging open innovation and collaborative eco-system that did not exist two decade ago).

Second, the value-seeking consumers are also set on using the empowering CITs and IBTPs to find, and extract, exceedingly higher values, regardless of their location and origins. They are also willing to collaborate with the local or international firms to maximize the magnitude of that value. Again, such behaviors were not observable two decades ago. This two-sided phenomenon goes far beyond the globalization of supplychains initiated mainly by larger firms - initially by only large MNEs, such as, General Electric and a few others - in search for higher competitiveness. It is the demand of the time-compressed, value-seeking, and possibly technology savvy consumers combined with their openness to collaboration with the newly empowered, if not embolden, new firms for meeting their expectations. These higher value objectives motivate people to utilize twine-related actions, obtain information about such firms from the far corners of the world on the one hand and participate in co-creating higher perceived values with them on the other hand. In turn, entrepreneurs of these entrepreneurial new firms are not only learning about, and leveraging, the received potent information, but also 
engage in collaborative co-creation with informed consumers that are embracing innovative newness.

The combination of this article and the above brief discussion offer a large window of opportunity to peer through the inner dynamics and the leading strategy of newer firms, where the decision, corresponding actions, and the consequent outcomes of each and all members of the firm contribute to their competitiveness and fruitful internationalization and the consequent customer satisfaction.

The third article in this issue is entitled as "The Roles of Leadership, Vision, and Empowerment in Born Global Companies" and is co-authored by the team of Soma Chhotray, Olof Sivertsson, and Joakim Tell. Stating that leadership is important in all firms, and especially critical to smaller and younger firms involved in global competition, may sound as an old cliché. However, the competitiveness of smaller firm, where resources are constrained, depends heavily on the effectiveness of the firm's leadership, clarity of its vision, and in the way by which they motivate and empower each and all members of the firm, employees, and stake-holder alike, to join their forces for enabling the firm to reach new heights. Naturally, the firm whose goal and vision are global need to meet the corresponding challenges that are nearly insurmountable, especially when facing the difficulties of increasing environmental complexity, strengthening competitive pressures emanating from global competitive players who set the competitive expectations and standards for all to follow, while also facing the liabilities of foreignness, smallness, and outsidership (Johanson and Vahlne 2009). For meeting such challenges and liabilities, firm are required to act as well-coordinated and equally well-supported teams (resembling a well trained and equipped small army set on accomplishing their goals), which can be accomplished only by dedicated contributions of all involved.

The in-depth examination of both the leadership and employees of two Swedish Born Global firms supports the finding and the lessons of this article. In relation to the arguments in previous articles, two reported findings are noteworthy: (i) That not only are clear vision and effective leadership necessary, but also, (ii) they alone are not sufficient for success in the international markets, as time-efficiency and effective efforts are of the essence. Seeking to establish collaborative learning with buyers, suppliers, and supporter for acquiring the timely and potent information that contribute readily to success, as well as avoiding mistakes, is bound to add to an aspiring firm's competitiveness and earn them the respect of all concerned. In addition to supportive and effective internal leadership, the next two articles discuss the nature of external support and examine the potency of such supports.

The fourth article in this issue is entitled as "Promotion Agencies and SMEs" Internationalization Process: A Blessing or a Curse?" and is authored by Noemie Dominguez. Theoretically, support institutions, especially those funded and supported by public funds, are both expected, and even mandated, to support value-creating entrepreneurial venture, as they create additional employment, income, and add to the public tax base. They may also create new intellectual property and initiate urban renewals. Five internationalizing SMEs were involved in the research of this article. As discussed earlier, in Part I, the traditional theories of international business would suggest that internationalizing SMEs should choose low-commitment and low-risk entry modes. Furthermore, they had pointed out the critical role of information and knowledge in the success of such internationalizing firms. Most low-commitment entry modes do not involve heavy capital investments and typical iSME can manage the 
smaller investment without external and time restrictive external assistance. However, in certain cases, where the control of assets and intellectual properties are necessary to both protecting the integrity of assets and preserving their long-term profitability, the requisite capital investment for high commitment entries must be made. That is where iSMEs can use the external support for augmenting their own capital funds and mitigating their risk-bearing capacity. However, external promotional agencies find themselves at a quandary in responding to such demands. On one hand, their mandate requires them to assist, and on the other hand, they are reluctant to step in in order to avoid the risks, as such risks may translate into losses of public funds. This article documents that reluctance. However, there is ample empirical evidence to suggest that the promotional agencies are well equipped for assisting iSME with information and knowledge of the market, even when primary market research is required. The last article in this issue documents a nearly reverse case that governmental support gave birth to a successful Born Global industry in Norway.

The fifth article in this issue is entitled as "The Birth and Development of a Born Global Industry: The Case of Microelectronics in Norway" and is co-authored by the team of Arild Aspelund, Mohammad Javadinia Azari, Andreas Flåt Aglen, and Sondre Gullord Graff. This article reports on a multilevel research documenting the creation of a born global industry. Naturally, the industry is composed of many entrepreneurially oriented born global firms that contribute to and support the industry's value chain. The global Micro-Electronics industry is a highly competitive, knowledge- and capitaintensive, and high-technology industry that is concentrated only in a handful of countries. For its high contributions and strategic importance, a few countries supported the creation of the industry without much success, which makes the life-long chronicle of the industry in Norway, from birth to its current stage, highly instructive. Two prominent factors combined to give rise to the birth and nurturing of the industry. The tireless efforts of highly committed and dedicated entrepreneurs pushing their visionary entrepreneurial initiatives relentlessly sowed $i$ the seeds and the unquestioned governmental support nurtured the initially feeble industry to its maturity and current globally viable position.

\section{Discussions and conclusion}

As stated earlier in the "Introduction," the main theme of this issue was how small and younger firm aspiring to grow internationally beyond a few easy-to-enter neighboring markets, or markets that share harmonized or nearly harmonized markets (e.g., the member of the European Union and the members of NAFTA, respectively) could expand into competitive global markets. The last four articles of this issue pointed to different, yet fruitfully promising, pathways to accomplish the task. They posited different potent suggestions, ranging from an insightful discussion of potent learning by "new" firms (see the article co-authored by Zahra, Zheng, and Yu) at one end, to the critical importance of effective entrepreneurial leadership and clear vision in smaller firms (see the article co-authored by Chhotray, Sivertsson, and Tell) and dedicated entrepreneurial efforts, combined and coordinated with their national government's unwavering support (see the article co-authored by Aspelund, Azari, Aglen, and Graff), at the other end. 
At the same time, the above articles supported, in principle, the concept of internationalizing firms defining their international operations at the most promising common overlaps between, and across, the emerging multidimensional and multilayered environments facing them (see Etemad 2017a for a detailed discussion). However, Dominguez questioned whether, or not, entrepreneurial initiatives are routinely supported by promotional institutions, whose public mandate is to support such valiant initiatives. These institutions' selective support may not be conducive to iSMEs' smooth and successful internationalization.

In combination, articles of this issue point to the need for finding, or creating, common and mutually beneficial areas, where the interest of all stake-holders coincides. In spite of the seeming difficulties, it is logical to suggest that successfully internationalized and growing firms (such as platform firms) have not only found such promising common overlapping areas in which to operate; but also, they are expanding the area's boundaries, mostly in cooperation and collaboration with others, to enable mutually beneficial growth for all concerned.

Conceptualizing the feasible pathway(s) and formulating a family of strategies to ensure continued growth pose theoretical and scholarly challenges. Naturally, the Journal of international Entrepreneurship calls on the scholarly community to take steps to meet those challenges. The journal is open to receiving articles with innovative concepts and ideas that expand our horizons.

Finally, the overall public policy implication of this issue is that the local and national governments need to support the creation and maintenance of promising common overlapping operating areas through their respective cohesive and conducive public policies to encourage entrepreneurial firms to adhere to such policies and to create incremental beneficial outcomes, regardless of their operational location and the firms' origins. Such incremental values accrue eventually to their respective citizen as consumers, suppliers, collaborator, and other stake-holder. Abstracting from the shortterm distributional disparities, the incremental benefits generated are bound to outweigh possible adversities.

\section{References}

Dana LP, Etemad H, Wright R (2001) Symbiotic business networks: collaboration between small and large firm. Thunderbird Int Bus Rev 43(4):481-500

Dana LP, Etemad H, Wright R (2008) Towards a paradigm of symbiotic entrepreneurship. Int J Entrep Small Bus 5(2):109-126

Etemad H (2004) International entrepreneurship as a dynamic adaptive system: towards a grounded theory. J Int Ent Spring 2004 2(1 \& 2):5-59

Etemad H (2007) The fastest growing SMEs in Canada: their strategies, e-commerce and network practices, in Susman G (ed.), Small and medium-sized enterprises and the global economy, Elgar Publishing, 103-124

Etemad H (2017a) The emergence of on-line global market place and the multilayered view of international entrepreneurship. J Int Entrep 15(4):353-365

Etemad H (2017b) Towards a conceptual multilayered framework of international entrepreneurship. J Int Entrep 15(3):229-238

Etemad H, Keen CH (2014). Entrepreneurial capital and internationalization of SMEs based in emerging economies in Chrysostome, E. \& Molz, R. (eds.), Building businesses in emerging and developing countries: challenges and opportunities., Routledge 7

Etemad H, Wu PC (2013) Revisiting aspects of born globals: young Canadian SMEs growing rapidly and becoming born globals in Etemad, H. (ed), Current issues in international entrepreneurship, Edward Elgar Publishing Ltd., Northampton, Mass 13-37 
Johanson J, Vahlne J-E (1977) The internationalization process of the firm: a model of knowledge development and increasing foreign market commitment. J Int Bus Stud 8(1):23-32

Johanson J, Vahlne J-E (1990) The mechanism of internationalization. Int Mark Rev 7(4):11-24

Johanson J, Vahlne JE (2003) Business relations learning and commitment in the internationalization process. J Int Entrep 1(1):83-101

Johanson J, Vahlne JE (2009) The Uppsala internationalization process model revisited: from liability of foreignness to liability of outsidership. J Int Bus Stud 40:1411-1431

Keen CH, Etemad H (2012) Rapid-growth and rapid internationalization of smaller enterprises from Canada. Manag Decis 50(4):569-590

Knight GA, Cavusgil ST (2004) Innovation, organizational capabilities, and the born-global firm. J Int Bus Stud 35(2):124-141

McDougall PP, Oviatt BM (2000) International entrepreneurship: the intersection of two research paths. Acad Manag J 43(5):902-906

McDougall PP, Shane S, Oviatt BM (1994) Explaining the formation of international new ventures: the limits of theories from international business research. J Bus Ventur 9(6):469-487

Moen Ø, Servais P (2002) Born global or gradual global? Examining the export behavior of small and medium-sized enterprises. J Int Mark 10(3):49-72

Oviatt BM, McDougall PP (1994) Toward a theory of international new ventures. J Int Bus Stud 25(1):45-64

Rennie MW (1993) Global competitiveness: born globals. McKinsey Q 4(4):45-52

Rialp A, Rialp J, Knight GA (2005) The phenomenon of early internationalizing firms: what do we know after a decade (1993-2003) of scientific inquiry? Int Bus Rev 14(2):147-166

Welch L, Luostarinen R (1988) Internationalization — evolution of a concept. J Gen Manag 14(2):34-55

Zahra SA (2005) A theory of international new ventures: a decade of research. J Int Bus Stud 36:20-28

Zahra SA, George G (2002) International entrepreneurship: the current status of the field and future research agenda. In: Hitt MA, Duane Ireland R, Sexton DL (eds) Strategic entrepreneurship: creating a new mindset. Blackwell, London 